\title{
Analisis Penerapan Prinsip Critical Non-Essentials pada Astra Honda Authorized Service Station (AHASS) di Kota Bogor
}

\author{
Moh. Firmansah \\ Departemen Manajemen, Fakultas Ekonomi dan Manajemen \\ Institut Pertanian Bogor \\ Kampus Darmaga Bogor 16680 \\ Pramono D Fewidarto \\ Departemen Manajemen, Fakultas Ekonomi dan Manajemen \\ Institut Pertanian Bogor \\ Kampus Darmaga Bogor 16680 \\ E-mail: pramdfew@yahoo.co.id
}

\begin{abstract}
The main problem in service industry are how to reduce inconvienity of customer while waiting for service, and this condition is also faced by Astra Honda Authorized Service Station (AHASS) Bogor. Critical Non-Essentials principles was used to help us to find supporting facilities needed to make customer feel more convenience while their motorcycles being maintained. Those supporting facilities are not directly related to the core of the business. The purposes of this study are 1) to identify the customer existing condition while waiting in Astra Honda Authorized Service Station (AHASS); 2) to analyze the facilities that customers of AHASS are needed using Critical Non-Essentials principles 3) to predict the increase of customer's convinience and satisfaction. Customer sample of this research was customers visited to AHASS, and willing to queue for service. Respondence sampled with accidental sampling mehod. Descriptive statistical analysis and Cross-tabulation analysis implemented to find some main priority facilities that should be completed to make the AHASS customer feel enjoy until their motorcycle finished.

Keywords: Convinience, comfort, Critical Non-Essentials, accidental sampling, descriptive statistics
\end{abstract}

\begin{abstract}
ABSTRAK
Problem utama yang dihadapi industri jasa adalah bagaimana mengurangi ketidaknyamanan konsumen ketika menunggu pelayanan, dan kondisi seperti ini juga dihadapi Astra Honda Authorized Service Station (AHASS) Bogor. Prinsip-prinsip Critical Non- Essentials digunakan untuk membantu dalam mengidentifikasi fasilitas penunjang yang dibutuhkan untuk membuat konsumen merasa lebih nyaman ketika menunggu sepeda motornya diperbaiki atau diservis. Tujuan penelitian ini adalah; 1) Mengidentifikasi kondisi konsumen ketika menunggu pelayanan di AHASS saat ini; 2) Menganalisis fasilitas yang dibutuhkan konsumen AHASS dengan mengaplikasikan prinsip-prinsip Critical NonEssentials; 3) Memprediksi peningkatan kenyamanan dan kepuasan konsumen. Sampel konsumen dari penelitian ini adalah konsumen yang datang ke AHASS dan bersedia antri menunggu pelayanan. Digunakan metode accidental sampling dalam menentukan responden yang akan menjadi sumber data atau informasi. Analisis statistik deskriptif dan tabulasi silang diterapkan untuk menentukan beberapa fasilitas prioritas utama yang dapat melengkapi yang ada, yang dapat membuat konsumen AHASS merasa senang sampai sepeda motor mereka selesai diperbaiki.

Kata kunci : Kenyamanan, Critical Non-Essentials, accidental sampling, statistika deskriptif, analisis tabulasi silang.
\end{abstract}




\section{Pendahuluan}

Persaingan yang semakin ketat terjadi dalam dunia otomotif khususnya untuk produk sepeda motor, karena produk ini merupakan sarana transportasi darat yang paling dominan dimiliki oleh masyarakat saat ini. Semakin banyaknya sepeda motor yang digunakan oleh masyarakat akan membuat kebutuhan akan perawatan dan perbaikan sepeda motor (bengkel) meningkat, akibatnya persaingan antara bengkel sepeda motor, baik yang tidak resmi maupun yang resmi meningkat. Untuk sepeda motor yang relatif baru, masyarakat cenderung melakukan servis rutin pada bengkel resmi yang dianggap dapat memberikan kepuasan dan kenyamanan. Bengkel resmi perlu mempertahankan pelanggannya agar tidak pergi begitu saja ke bengkel resmi yang lain. Konsumen yang nyaman dan betah akan berkunjung kembali ke bengkel yang sama untuk melakukan servis dan menjadi pelanggan yang loyal. Loyalitas pelanggan akan memiliki hubungan positif dengan profitabilitas perusahaan (Helgesen 2006). Semakin tinggi kepuasan pelanggan, semakin tinggi juga loyalitasnya, dan semakin tinggi loyalitas pelanggan, semakin tinggi profitabilitas yang diperoleh perusahaan.

Tabel 1. Jumlah produksi sepeda motor di Indonesia (2008 - 2013)

\begin{tabular}{lccc}
\hline Tahun & Produksi (unit) & Pasar Lokal (unit) & $\begin{array}{c}\text { Ekspor } \\
\text { (unit) }\end{array}$ \\
\hline 2008 & 6264265 & 6215831 & 64968 \\
2009 & 5884021 & 5881777 & 29815 \\
2010 & 7395390 & 7398644 & 29395 \\
2011 & 8006293 & 8043535 & 31357 \\
2012 & 4311019 & 7064457 & 77129 \\
2013 (Jan) & 662920 & 646082 & 3901 \\
\hline
\end{tabular}

Sumber : Asosiasi Industri Sepeda Motor Indonesia-AISI (2013)

PT Astra Honda Motor akan mendapatkan hasil maksimal jika memberikan pelayanan yang baik, sebelum, selama, dan terutama setelah penjualan, yang biasa disebut dengan layanan purna jual seperti yang dilakukan Astra Honda Authorized Service Station (AHASS) . AHASS merupakan bagian jaringan pemeliharaan ( $\mathrm{H} 2)$ atau disebut juga sebagai bengkel resmi dari jaringan servis sepeda motor Honda. AHASS memiliki cabang pada tiap provinsi yang dikelola oleh PT Astra Honda Motor, sedangkan AHASS-AHASS lain yang bukan cabang merupakan kemitraan yang dijalin oleh AHASS cabang dengan pemilik modal di suatu kota (franchise). Pada 2012 AHASS adalah yang terbaik dalam memberikan pelayanan kepada pelanggan (Customer Satisfaction Index No. 1), yaitu dengan memberikan perbaikan dan pelayanan terbaik di bengkel resmi Honda (AHM 2013). Dengan demikian persaingan akan terjadi antara sesama AHASS, oleh karena itu setiap AHASS harus bekerja keras untuk menjaga pelanggan agar tetap setia sama seperti yang dilakukan untuk mendapatkan konsumen baru.

Konsumen yang melakukan servis di AHASS tidak hanya ingin sepeda motornya dirawat atau diperbaiki, namun konsumen juga menginginkan pelayanan yang baik dalam kondisi yang nyaman, terutama saat menunggu sepeda motornya diperbaiki. Kejenuhan akan timbul dikarenakan waktu tunggu yang cukup lama untuk menyelesaikan servis sepeda motor. AHASS perlu memahami bentuk fasilitas atau 
pelayanan seperti apa yang tepat digunakan untuk menghilangkan kejenuhan konsumen. Pelayanan yang perlu ditingkatkan tersebut bersifat non-essentials, karena tidak terkait langsung dengan inti bisnis AHASS. Pelayanan yang sifatnya non-essentials namun sangat menentukan kenyamanan konsumen tersebut dinamakan sebagai Critical Non-Essentials (CNE), yaitu hal-hal kecil di luar bisnis inti yang menambahkan banyak nilai bagi konsumen maupun pelaku bisnis sehingga pada akhirnya dapat menentukan keberhasilan suatu bisnis (Lund 2007).

Tujuan dari kajian ini adalah : 1) Mengidentifikasi kondisi konsumen ketika menunggu pelayanan di AHASS saat ini; 2) Menganalisis fasilitas yang dibutuhkan konsumen AHASS dengan mengaplikasikan prinsip-prinsip Critical Non-Essentials; 3) Memprediksi peningkatan kenyamanan dan kepuasan konsumen.

\section{Metode Penelitian}

Penelitian ini dilakukan di bengkel-AHASS d Kota Bogor. Pemilihan lokasi dilakukan secara sengaja dengan pertimbangan AHASS yang berada di kota Bogor lebih banyak dibandingkan bengkel resmi lainnya. Kegiatan penelitian ini dilaksanakan pada bulan Mei sampai dengan bulan September 2013. Metode pengumpulan data primer dilakukan melalui wawancara menggunakan bantuan kuesioner. Sedangkan metode pengumpulan data sekunder dilakukan melalui studi kepustakaan serta pencarian data dari internet.

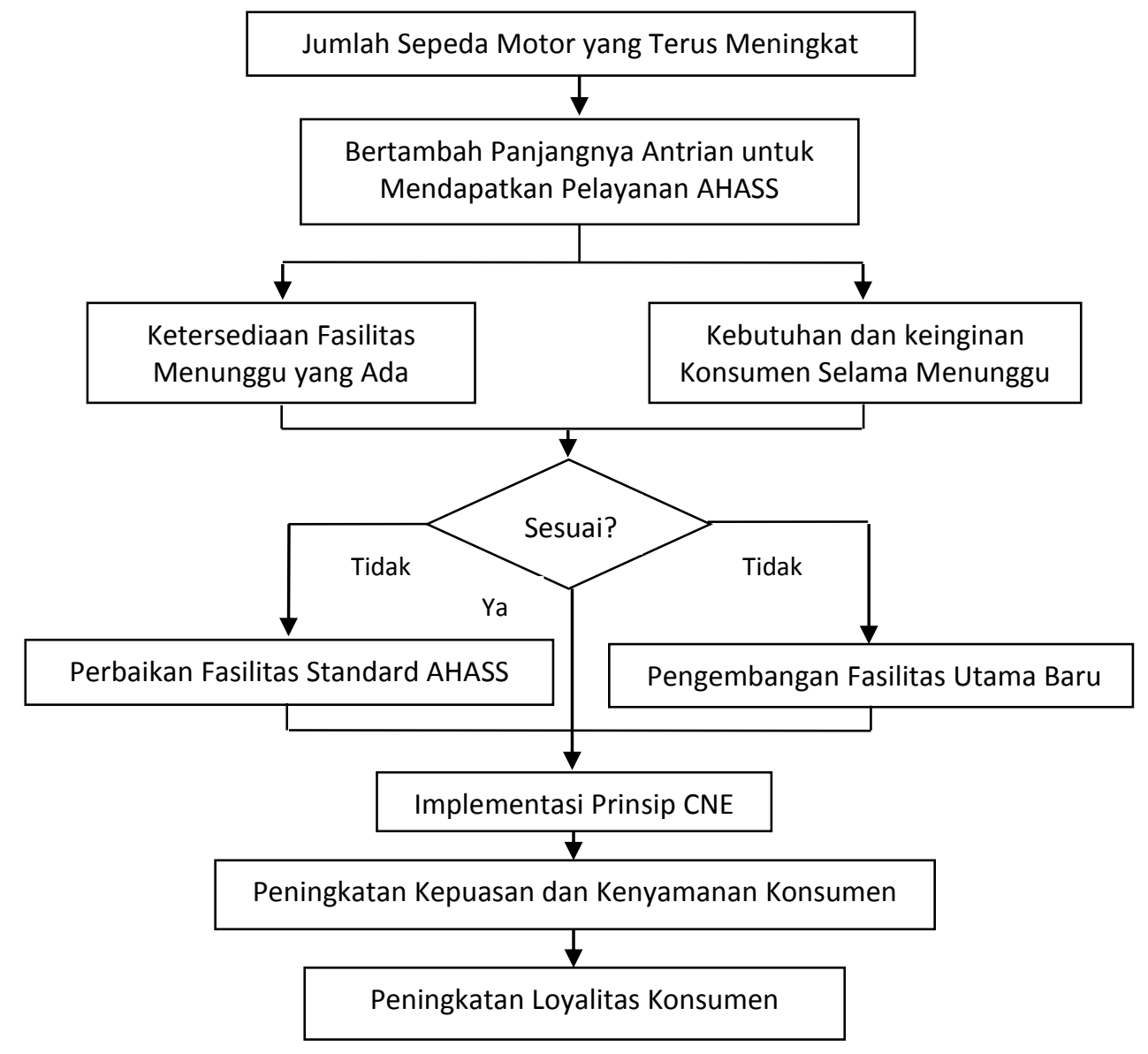

Gambar 1. Kerangka pemikiran penelitian 
Sample dalam penelitian ini terdiri atas dua kelompok, yaitu sample AHASS dan sample responden dari konsumen AHASS di Bogor yang terpilih. Penetapan sample AHASS dilakukan dengan mengklasifikasikan bengkel-AHASS di Kota Bogor berdasarkan kapasitas bengkel (jumlah lini pelayanan) dan jumlah pengunjung per bulan agar lebih mudah untuk menentukan jumlah responden pada masing-masing AHASS. Metode pengambilan sample AHASS adalah purposive sampling, dimana kriteria bengkel yang menjadi sample adalah bengkel dengan jumlah pengunjung terbanyak selama satu bulan. Diasumsikan bahwa semakin banyak pengunjung, maka akan semakin banyak yang harus mengantri dan menunggu sepeda motornya diperbaiki. Sedangkan pemilihan responden konsumen dilakukan secara accidental sampling. Responden penelitian diambil secara proporsional menurut rata-rata jumlah kunjungan konsumen per bulan dari masing-masing bengkel sehingga diperoleh jumlah konsumen yang akan menjadi responden dari setiap bengkel.

Uji validitas terhadap butir-butir pertanyaan kuesioner yang ditujukan kepada konsumen AHASS dalam penelitian ini diukur dengan menggunakan teknik korelasi Product Moment Pearson. Sedangkan untuk uji reliabilitas yang menunjukkan konsistensi terhadap kuesioner yang digunakan dalam penelitian ini diukur dengan menggunakan teknik Alpha Cronbach. Metode pengolahan dan analisis data hasil pengisian kuesioner oleh konsumen AHASS adalah Metode Analisis Statistika Deskriptif dan Crosstab. Analisis gap digunakan untuk mengukur kesenjangan yang terjadi antara kondisi aktual AHASS dengan harapan dan keinginan konsumen, dan melakukan perbaikan model CNE.

\section{Hasil dan Pembahasan}

III.1. Gambaran Umum Tempat Penelitian

Kota Bogor memiliki 15 AHASS dengan karakteristik dan kapasitas yang berbedabeda. Bengkel yang menjadi objek penelitian dibagi menjadi 3 kelompok berdasarkan tingkat keramaian konsumen per bulan, kemudian dipilih 2 kelompok bengkel yaitu bengkel ramai dan sangat ramai. Pemilihan kedua kelompok ini didasari asumsi bahwa semakin banyak jumlah pengunjung, semakin panjang antrian dan waktu tunggu yang akan dialami konsumen.

Penelitian ini mengambil 5 bengkel dengan jumlah pengunjung terbanyak pada bulan Mei 2013 sebagai sampel AHASS. Dengan demikian bengkel-bengkel yang dipilih adalah Guna Motor, Anugrah Sejahtera, Daya Motor, Murni Motor, dan Sanprima Sentosa.

Tabel 2. Pengelompokan bengkel

\begin{tabular}{lccc}
\hline Kelompok & $\begin{array}{c}\text { Rentang jumlah } \\
\text { konsumen per bulan } \\
\text { (orang) }\end{array}$ & $\begin{array}{c}\text { Jumlah bengkel } \\
\text { (unit) }\end{array}$ & $\begin{array}{c}\text { Persentase } \\
\text { (\%) }\end{array}$ \\
\hline Sedang & $650-1300$ & 10 & 66.6 \\
Ramai & $1300-1950$ & $\mathbf{4}$ & $\mathbf{2 6 . 6}$ \\
Sangat ramai & $\mathbf{1 9 5 1 - 2 ~ 6 0 0}$ & $\mathbf{1}$ & $\mathbf{6 . 6}$ \\
\hline Jumlah & & $\mathbf{1 5}$ & $\mathbf{1 0 0}$ \\
\hline
\end{tabular}




\section{III.2. Penerapan Prinsip CNE}

Experiential marketing dapat sangat berguna untuk sebuah perusahaan yang ingin meningkatkan merek yang berada pada tahap penurunan, membedakan produk mereka dari produk pesaing, menciptakan sebuah citra dan identitas untuk sebuah perusahaan, meningkatkan inovasi dan membujuk pelanggan untuk mencoba dan membeli produk. Hal yang terpenting adalah menciptakan pelanggan yang loyal. Pelanggan mencari perusahaan dan merek-merek tertentu untuk dijadikan bagian dari hidup mereka. Pelanggan menginginkan agar perusahaan dan merek yang ada dapat berhubungan dengan hidup mereka (pelanggan), mengerti mereka, menyesuaikan dengan kebutuhan mereka dan membuat hidup mereka lebih terpenuhi. Dalam era informasi, teknologi, perubahan dan pilihan, setiap perusahaan perlu lebih selaras dengan para pelanggan dan pengalaman yang diberikan produk atau jasa mereka (Rini 2009).

Ziqi Wu et al. (2013), menerangkan bahwa perlu adanya inovasi desain agar dapat meningkatkan pelayanan terhadap konsumen yang berkunjung. Pelayananpelayanan tersebut bersifat unik dan berbeda agar konsumen merasa puas dan nyaman akan pelayanan yang telah diberikan. CNE diterapkan oleh bengkel yang menjadi objek penelitian dengan menyediakan pelayanan dan fasilitas yang tidak terkait langsung dengan jasa utama dari bengkel tersebut. Bengkel-bengkel yang menjadi objek penelitian telah menyediakan fasilitas-fasilitas di ruang tunggu yang menunjang para konsumennya agar dapat merasa nyaman dan tidak bosan selama berada di ruang tunggu. Fasilitas-fasilitas tersebut dapat dikategorikan menjadi tiga bagian yaitu media komunikasi dan entertainment, fasilitas ruangan, dan fasilitas penunjang.

\section{III.3. Tabulasi Silang}

Penilaian konsumen terhadap kenyamanan dilihat dari fasilitas-fasilitas menunggu yang disediakan bengkel, baik bengkel ramai maupun sangat ramai. Fasilitas-fasilitas ini yang membuat konsumen merasa betah dan nyaman selama berada di ruang tunggu. Berdasarkan data yang tersaji, walau sebagian besar konsumen merasakan cukup nyaman menunggu, namun konsumen pada bengkel yang sangat ramai merasakan kenyamanan menunggunya masih bisa ditingkatkan ke level tertinggi dibandingkan dengan konsumen bengkel ramai.

Tabel 3. Frekuensi tingkat kenyamanan konsumen

\begin{tabular}{lcccccccccc}
\hline \multirow{2}{*}{ Konsumen } & \multicolumn{4}{c}{ Kenyamanan bengkel ramai (\%) } & \multicolumn{4}{c}{ Kenyamanan bengkel sangat ramai (\%) } \\
\cline { 2 - 11 } & $\mathbf{1}$ & $\mathbf{2}$ & $\mathbf{3}$ & $\mathbf{4}$ & $\mathbf{5}$ & $\mathbf{1}$ & $\mathbf{2}$ & $\mathbf{3}$ & $\mathbf{4}$ & $\mathbf{5}$ \\
\hline Tingkat & 0 & 10.0 & 36.0 & 19.0 & 5.0 & 5.0 & 5.0 & 17.0 & 3.0 & 0 \\
kenyamanan & & & 70.0 & & & \multicolumn{5}{c}{30.0} \\
\hline
\end{tabular}

Keterangan : 1 = tidak nyaman, 2 = kurang nyaman, 3 = cukup nyaman, 4 = nyaman, 5 = sangat nyaman

Tingkat keramaian konsumen mempengaruhi kemampuan untuk memberi kenyamanannya, karena pada bengkel sangat ramai antrian yang terjadi lebih panjang dan banyak orang yang menunggu di ruang tunggu. Terlebih jika prinsip CNE tidak diterapkan di ruang tunggu dan bengkel kurang memperhatikan kenyamanan konsumennya karena terlalu memfokuskan pada layanan inti yaitu perbaikan dan 
perawatan sepeda motor. Seringkali kenyamanan konsumen di ruang tunggu kurang diperhatikan karena dianggap dengan fasilitas seadanya saja konsumen akan tetap datang ke bengkel tersebut. Namun dalam jangka panjang hal ini dapat mengurangi daya saing AHASS tersebut.

Tabel 4. Kenyamanan konsumen bengkel ramai terkait perilaku konsumen

\begin{tabular}{lcccccc}
\hline Perilaku & \multicolumn{4}{c}{ Tingkat Kenyamanan (\%) } & & Total (\%) \\
& $\begin{array}{c}\text { Tidak } \\
\text { nyaman }\end{array}$ & $\begin{array}{c}\text { Kurang } \\
\text { nyaman }\end{array}$ & $\begin{array}{c}\text { Cukup } \\
\text { nyaman }\end{array}$ & Nyaman & $\begin{array}{c}\text { Sangat } \\
\text { nyaman }\end{array}$ & Tom \\
\hline Merokok & 0 & 2.9 & 2.9 & 7.1 & 0 & 12.9 \\
Menonton TV & 0 & 0 & 20.0 & 7.1 & 2.9 & 30.0 \\
Mendengarkan musik & 0 & 1.4 & 0 & 1.4 & 1.4 & 4.3 \\
Tidur & 0 & 0 & 0 & 0 & 0 & 0 \\
Membaca & 0 & 0 & 5.7 & 1.4 & 0 & 7.1 \\
majalah/koran & & & & & & \\
Memperhatikan proses & 0 & 0 & 0 & 1.4 & 1.4 & 2.9 \\
servis & 0 & 10.0 & 22.9 & 8.6 & 1.4 & 42.9 \\
Bermain dengan ponsel & 0 & 14.3 & 51.4 & 27.1 & 7.1 & 100 \\
Total (\%) & 0 & &
\end{tabular}

Keterkaitan antara kenyamanan konsumen dengan perilaku konsumen dapat dilihat berdasarkan data yang tersaji pada Tabel 4, dan didasarkan pada hipotesis awal bahwa terdapat hubungan yang signifikan antara kenyamanan konsumen dengan perilaku konsumen. Pada Tabel 4 diperlihatkan bahwa dari 70 konsumen bengkel ramai, sebanyak $14.3 \%$ konsumen menyatakan kurang nyaman berada di bengkel ramai, namun sebanyak $85.6 \%$ konsumen merasa cukup nyaman sampai dengan sangat nyaman selama menunggu di bengkel. Mayoritas konsumen melakukan aktivitas bermain dengan ponsel dan menonton tv selama berada di ruang tunggu.

Diduga terdapat keterkaitan antara jenis pekerjaan dengan penilaian tingkat kenyamanan menunggu pada bengkel ramai. Karyawan swasta yang biasa berada pada tekanan waktu kerja yang tinggi menuntut tingkat kenyamanan pada ruang tunggu yang lebih tinggi disbanding pekerjaan lainnya. Tabulasi silang antara jenis pekerjaan dengan kenyamanan konsumen selama menunggu menunjukkan nilai Asymp Sig sebesar 0.03 yang mengindikasikan jenis pekerjaan memiliki keterkaitan dengan kenyamanan konsumen selama menunggu.

Berdasarkan pada hipotesis awal bahwa terdapat hubungan yang signifikan antara kenyamanan konsumen dengan lama proses pengerjaan servis. Namun dari apa yang tersaji pada Tabel 5, tidak ada pola tertentu yang menggambarkan hubungan kedua hal tersebut. Hal ini mengindikasikan bahwa bengkel dengan mekanik yang dapat menyelesaikan proses servis dengan sangat cepat, belum tentu konsumennya merasa sangat nyaman selama menunggu. Kondisi ini bisa saja terjadi karena bengkel dengan lama proses pengerjaan $>46$ menit memperhatikan kenyamanan konsumennya dengan menyediakan fasilitas yang lebih baik dibandingkan bengkel dengan lama proses pengerjaan < 30 menit. Hasil uji Asymp Sig. menunjukkan nilai sebesar 0.31 yang mengindikasikan bahwa tidak ada keterkaitan antara lama proses pengerjaan servis sepeda motor dengan tingkat kenyamanan konsumen. 
Tabel 5. Kenyamanan konsumen bengkel ramai terkait lama proses pengerjaan servis

\begin{tabular}{lcccccc}
\hline $\begin{array}{l}\text { Lama proses } \\
\text { pengerjaan }\end{array}$ & $\begin{array}{c}\text { Tidak } \\
\text { nyaman }\end{array}$ & $\begin{array}{c}\text { Tingkat Kenyamanan (\%) } \\
\text { nyaman }\end{array}$ & $\begin{array}{c}\text { Cukup } \\
\text { nyaman }\end{array}$ & Nyaman & $\begin{array}{c}\text { Sangat } \\
\text { nyaman }\end{array}$ & Total (\%) \\
\hline$<30$ menit & 0 & 2.9 & 12.9 & 7.1 & 0 & 22.9 \\
$31 \quad-\quad 45$ & 0 & 8.6 & 32.9 & 8.6 & 4.3 & 54.3 \\
menit & 0 & 2.9 & 5.7 & 11.4 & 2.9 & 22.9 \\
$>46$ menit & 0 & 14.3 & 51.4 & 27.1 & 7.1 & 100 \\
Total (\%) & 0 & & & & & \\
\hline
\end{tabular}

Keterkaitan antara kenyamanan konsumen dengan perilaku konsumen dapat dilihat berdasarkan data yang tersaji pada Tabel 6, dimana tampak bahwa dari 30 konsumen bengkel sangat ramai, perilaku konsumen selama menunggu terbagi hampir merata mulai dari merokok sampai dengan bermain dengan ponsel, kecuali tidur. Sebanyak 33.4\% konsumen merasa tidak nyaman dan kurang nyaman selama berada di bengkel sangat ramai, sedangkan $66.7 \%$ konsumen menyatakan cukup nyaman dan nyaman. Konsumen bengkel sangat ramai tidak satupun yang merasa sangat nyaman berada di bengkel, hal ini karena bengkel sangat ramai kurang menyediakan fasilitas yang memadai untuk konsumen yang banyak. Kondisi ini perlu diperhatikan oleh bengkel sangat ramai, karena berbeda dengan kondisi pada bengkel ramai yang tingkat kenyamanannya lebih baik.

Tabel 6. Kenyamanan konsumen bengkel sangat ramai terkait perilaku konsumen

\begin{tabular}{|c|c|c|c|c|c|c|}
\hline \multirow[b]{2}{*}{ Perilaku } & \multicolumn{5}{|c|}{ Tingkat Kenyamanan (\%) } & \multirow[b]{2}{*}{ Total (\%) } \\
\hline & Tidak nyaman & $\begin{array}{c}\text { Kurang } \\
\text { nyaman }\end{array}$ & $\begin{array}{c}\text { Cukup } \\
\text { nyaman }\end{array}$ & Nyaman & $\begin{array}{c}\text { Sangat } \\
\text { nyaman }\end{array}$ & \\
\hline Merokok & 0 & 3.3 & 10.0 & 0 & 0 & 13.3 \\
\hline Menonton TV & 3.3 & 6.7 & 6.7 & 0 & 0 & 16.7 \\
\hline $\begin{array}{l}\text { Mendengarkan } \\
\text { musik }\end{array}$ & 3.3 & 0 & 10.0 & 0 & 0 & 13.3 \\
\hline Tidur & 0 & 0 & 0 & 0 & 0 & 0 \\
\hline $\begin{array}{l}\text { Membaca } \\
\text { majalah/koran }\end{array}$ & 6.7 & 0 & 16.7 & 0 & 0 & 23.3 \\
\hline $\begin{array}{l}\text { Memperhatikan } \\
\text { proses servis }\end{array}$ & 0 & 0 & 6.7 & 3.3 & 0 & 10.0 \\
\hline $\begin{array}{l}\text { Bermain dengan } \\
\text { ponsel }\end{array}$ & 3.3 & 6.7 & 6.7 & 6.7 & 0 & 23.3 \\
\hline Total (\%) & 16.7 & 16.7 & 56.7 & 10,0 & 0 & 100 \\
\hline
\end{tabular}

Tabulasi silang antara jenis pekerjaan dengan kenyamanan konsumen selama menunggu pada bengkel AHASS sangat ramai menunjukkan nilai Asymp Sig. sebesar 0.86 yang mengindikasikan jenis pekerjaan tidak memiliki keterkaitan dengan kenyamanan konsumen selama menunggu di bengkel kategori ini. Hal ini berbeda dengan apa yang terjadi pada bengkel AHASS dengan kategori ramai. 
174|Firmansah, Fewidarto - Analisis Penerapan Princip Critical Non-Essentials

Tabel 7. Kenyamanan konsumen bengkel sangat ramai terkait lama proses pengerjaan servis

\begin{tabular}{lcccccc}
\hline \multirow{2}{*}{$\begin{array}{l}\text { Lama proses } \\
\text { pengerjaan }\end{array}$} & $\begin{array}{c}\text { Tidak } \\
\text { nyaman }\end{array}$ & $\begin{array}{c}\text { Kurang } \\
\text { nyaman }\end{array}$ & $\begin{array}{c}\text { Cukup } \\
\text { nyaman }\end{array}$ & Nyaman & $\begin{array}{c}\text { Sangat } \\
\text { nyaman }\end{array}$ & Total (\%) \\
\hline$<30$ menit & 16,7 & 16.7 & 56.7 & 10.0 & 0 & 100 \\
\hline Total (\%) & 16.7 & 16.7 & 56.7 & 10.0 & 0 & 100 \\
\hline
\end{tabular}

Hasil tabulasi silang antara lama proses pengerjaan servis bengkel AHASS kategori sangat ramai dengan tingkat kenyamanan konsumen tidak dapat menunjukkan nilai Asymp Sig. Hal ini terjadi karena variabelnya hanya berisikan 1 nilai konstan. Pada Tabel 8 terlihat bahwa hanya sebanyak 10.0\% konsumen yang merasa nyaman selama berada di bengkel, dan sebanyak $33.4 \%$ konsumen merasa tidak nyaman dan kurang nyaman selama berada di bengkel.

Tabel 8. Frekuensi tingkat kepuasan konsumen

\begin{tabular}{lllllllllll}
\hline \multirow{2}{*}{ Konsumen } & \multicolumn{1}{c}{ TingkatkKepuasan bengkel ramai (\%) } & \multicolumn{7}{c}{ Tingkat kepuasan bengkel sangat ramai (\%) } \\
\cline { 2 - 11 } & $\mathbf{1}$ & $\mathbf{2}$ & $\mathbf{3}$ & $\mathbf{4}$ & $\mathbf{5}$ & $\mathbf{1}$ & $\mathbf{2}$ & $\mathbf{3}$ & $\mathbf{4}$ & $\mathbf{5}$ \\
\hline Tingkat & 1 & 3 & 33 & 31 & 2 & 0 & 1 & 15 & 8 & 6 \\
kepuasan & & & 70 & & & & & 30 & \\
\hline
\end{tabular}

Keterangan : 1 = tidak puas, 2 = kurang puas, $3=$ cukup puas, $4=$ puas, $5=$ sangat puas

Penilaian konsumen terhadap kepuasan dilihat dari hasil perbaikan dan perawatan sepeda motor, kualitas mekanik bengkel, dan kelengkapan peralatan jasa servis sepeda motor. Berdasarkan data yang tersaji, dapat disimpulkan bahwa kedua bengkel sangat memperhatikan kualitas jasa utama dari servis sepeda motor, sehingga kepuasan konsumennya cukup tinggi. Kecenderungan tingkat kepuasan konsumen yang tidak jauh berbeda di setiap bengkel pada berbagai kategori tingkat keramaian, hal ini mengindikasikan bahwa pelayanan essentials yang diberikan bengkel tidak terlalu berbeda kualitasnya. Oleh karena itu, saat ini kualitas pelayanan essentials saja tidak cukup untuk memenuhi kepuasan dan kenyamanan konsumen, sehingga bengkel harus berusaha meningkatkan pelayanan lain selain pelayanan essentials, yaitu pelayanan non-essentials.

Tabel 9. Kepuasan konsumen bengkel ramai dan sangat ramai terkait rataan pengeluaran perbulan

\begin{tabular}{lcccccc}
\hline \multirow{2}{*}{$\begin{array}{l}\text { Rataan pengeluaran } \\
\text { perbulan }\end{array}$} & \multicolumn{5}{c}{ Tingkat Kepuasan (\%) } & \multirow{2}{*}{ Total (\%) } \\
\cline { 2 - 5 } & $\begin{array}{c}\text { Tidak } \\
\text { puas }\end{array}$ & $\begin{array}{c}\text { Kurang } \\
\text { puas }\end{array}$ & $\begin{array}{c}\text { Cukup } \\
\text { puas }\end{array}$ & Puas & $\begin{array}{c}\text { Sangat } \\
\text { puas }\end{array}$ & \\
\hline < Rp 50 000 & 1.0 & 0 & 5.0 & 4.0 & 0 & 10.0 \\
Rp 50 001 - Rp 100 000 & 0 & 3.0 & 24.0 & 16.0 & 5.0 & 48.0 \\
Rp 100 001 - Rp 200 000 & 0 & 1.0 & 15.0 & 16.0 & 3.0 & 35.0 \\
$>$ Rp 200 001 & 0 & 0 & 4.0 & 3.0 & 0 & 7.0 \\
\hline Total (\%) & 1.0 & 4.0 & 48.0 & 39.0 & 8.0 & 100 \\
\hline
\end{tabular}

Diduga terdapat hubungan yang signifikan antara kepuasan konsumen dengan rataan pengeluaran perbulan untuk servis sepeda motor. Konsumen dengan tingkat pengeluaran yang berbeda menuntut tingkat kepuasan yang berbeda. Data yang tersaji pada Tabel 9 menunjukkan bahwa dari 100 konsumen bengkel ramai dan sangat ramai, sebanyak $95.0 \%$ merasa cukup puas sampai dengan sangat puas dengan pelayanan servis bengkel, dan hanya sebanyak $5.0 \%$ yang merasa tidak puas dan kurang puas 
dengan pelayanan servis sepeda motor. Tabulasi silang antara rataan pengeluaran perbulan untuk servis sepeda motor dengan kepuasan konsumen menunjukkan nilai Asymp Sig. sebesar 0.34 yang mengindikasikan rataan pengeluaran perbulan tidak memiliki keterkaitan signifikan dengan kepuasan konsumen. Hal ini berarti kepuasan konsumen tidak terkai dengan rataan pengeluaran perbulan untuk servis sepeda motor. Konsumen dengan rataan pengeluaran perbulan untuk servis sepeda motor berapapun, tingkat kepuasannya menyebar dari tidak puas sampai dengan sangat puas.

Tabel 10. Kepuasan konsumen bengkel ramai dan sangat ramai terkait jumlah lini bengkel

\begin{tabular}{lcccccc}
\hline \multirow{2}{*}{$\begin{array}{l}\text { Jumlah lini } \\
\text { bengkel }\end{array}$} & $\begin{array}{c}\text { Tidak } \\
\text { puas }\end{array}$ & $\begin{array}{c}\text { Kurang } \\
\text { puas }\end{array}$ & $\begin{array}{c}\text { Cukup } \\
\text { puas }\end{array}$ & Puas & $\begin{array}{c}\text { Sangat } \\
\text { puas }\end{array}$ & Total (\%) \\
\hline 6-8 lini & 1.0 & 3.0 & 25.0 & 20.0 & 0 & 49.0 \\
9-10 lini & 0 & 1.0 & 23.0 & 19.0 & 8,0 & 51.0 \\
\hline Total (\%) & 1.0 & 4.0 & 48.0 & 39.0 & 8,0 & 100 \\
\hline
\end{tabular}

Keterkaitan antara kepuasan konsumen dengan jumlah lini bengkel dapat dilihat berdasarkan data yang tersaji pada Tabel 10, dan didasarkan pada hipotesis awal bahwa terdapat hubungan yang signifikan antara kepuasan konsumen dengan jumlah lini bengkel. Konsumen bengkel dengan 9-10 lini yang menyatakan puas dan sangat puas sebesar $27.0 \%$, sedang yang menyatakan tidak puas dan kurang puas sebesar $1.0 \%$. Konsumen bengkel dengan 6-8 lini hanya sebesar $20.0 \%$ yang menyatakan puas dan sangat puas sedangkan konsumen yang menyatakan tidak puas dan sangat tidak sebesar $4.0 \%$. Berdasarkan hasil tersebut dapat disimpulkan bahwa konsumen bengkel ramai dan sangat ramai merasa lebih puas dengan jumlah lini bengkel yang banyak. Hasil uji menunjukkan nilai Asymp Sig. sebesar 0.03 yang mengindikasikan jumlah lini bengkel memiliki keterkaitan yang signifikan dengan tingkat kepuasan konsumen. Jumlah lini bengkel yang lebih banyak dapat mempercepat proses pengerjaan servis dan dapat mengurangi waktu tunggu konsumen selama menunggu, sehingga dengan jumlah lini yang banyak konsumen merasa lebih puas karena waktu tunggunya akan berkurang.

Tabel 11. Frekuensi tingkat kesabaran konsumen

\begin{tabular}{|c|c|c|c|c|c|c|c|c|c|c|}
\hline \multirow{2}{*}{ Konsumen } & \multicolumn{5}{|c|}{ Kesabaran bengkel ramai (\%) } & \multicolumn{5}{|c|}{ Kesabaran bengkel sangat ramai (\%) } \\
\hline & 1 & 2 & 3 & 4 & 5 & 1 & 2 & 3 & 4 & 5 \\
\hline Tingkat & 15 & 38 & 5 & 11 & 1 & 4 & 23 & 2 & 1 & 0 \\
\hline kesabaran & \multicolumn{5}{|c|}{70} & \multicolumn{5}{|c|}{30} \\
\hline
\end{tabular}

Keterangan : 1 = < 30 menit, 2 = 31-60 menit, 3 = 61-90 menit, 4 = 91-120 menit, 5 = > 120 menit

Penilaian konsumen terhadap kesabaran dilihat dari beberapa karakteristik konsumen dan karakteristik bengkel tersebut. Karakteristik konsumen dibagi berdasarkan jenis kelamin dan jenis ponsel yang digunakan, sedangkan karakteristik bengkel dibagi berdasarkan lama proses pengerjaan servis dan rataan input perhari bengkel. Berdasarkan data yang tersaji, dapat disimpulkan bahwa pada kedua bengkel, sebagian besar konsumennya mau menunggu selama 31 - 60 menit. Pengadaan fasilitas-fasilitas yang kritis terhadap kenyamanan tetapi tidak terkait langsung dengan 
pekerjaan utama (CNE) yang tepat diharapkan dapat meningkatkan kesabaran konsumen berada dalam ruang tunggu selama proses perbaikan dan perawatan sepeda motor berjalan.

Tabel 12. Kesabaran konsumen bengkel ramai dan sangat ramai terkait jenis ponsel

\begin{tabular}{lcccccc}
\hline & \multicolumn{5}{c}{ Batas kesabaran menunggu (\%) } & \multirow{2}{*}{ Total (\%) } \\
\cline { 2 - 6 } Jenis ponsel & $<\mathbf{3 0}$ menit & $\begin{array}{c}\mathbf{3 1 - 6 0} \\
\text { menit }\end{array}$ & $\begin{array}{c}\mathbf{6 1 - 9 0} \\
\text { menit }\end{array}$ & $\begin{array}{c}\mathbf{9 1 - 1 2 0} \\
\text { menit }\end{array}$ & $\begin{array}{c}>\mathbf{1 2 1} \\
\text { menit }\end{array}$ & \\
\hline Smartphone & 15.0 & 49.0 & 5.0 & 9.0 & 1.0 & 79.0 \\
Ponsel musik & 3.0 & 10.0 & 1.0 & 3.0 & 0 & 17.0 \\
Ponsel games & 0 & 0 & 1.0 & 0 & 0 & 1.0 \\
Ponsel biasa & 1.0 & 2.0 & 0 & 0 & 0 & 3.0 \\
\hline Total (\%) & 19.0 & 61.0 & 7.0 & 12.0 & 1.0 & 100 \\
\hline
\end{tabular}

Diduga terdapat hubungan yang signifikan antara kesabaran konsumen dengan jenis ponsel yang digunakan. Kesabaran konsumen bengkel ramai dan sangat ramai terkait jenis ponsel memperlihatkan penyebaran yang tidak merata, karena sebanyak 79.0\% konsumen bengkel menggunakan smartphone. Mayoritas konsumen yang menggunakan smartphone sabar menunggu sambil bermain dengan ponselnya, dan terdapat $15.0 \%$ konsumen yang sabar menunggu $>1$ jam. Konsumen yang menggunakan smartphone dianggap lebih sabar, karena dapat menghilangkan rasa jenuh selama menunggu dengan cara internetan, bermain games atau sekedar menelpon orang lain. Konsumen yang menggunakan ponsel musik dianggap cukup sabar, karena terdapat 3.0\% yang sabar menunggu $>1$ jam. Konsumen ini dapat menghilangkan kejenuhan dengan mendengarkan musik selama sepeda motornya diperbaiki. Bengkel dapat menyediakan fasilitas tambahan berupa peminjaman music/radio head set agar konsumen lebih nyaman menikmati musik pilihannya. Berdasarkan data hanya terdapat $1.0 \%$ konsumen yang menggunakan ponsel dengan banyak fitur permainan atau games pada ponselnya. Hal ini karena tidak ada konsumen bengkel yang masih anak-anak. Konsumen yang menggunakan ponsel biasa hanya sabar menunggu maksimal 1 jam, karena yang bisa dilakukan dengan ponselnya hanya menelpon atau sms.

Konsumen yang menggunakan smartphone lebih sabar dibandingkan konsumen lainnya, karena jika dihitung pada tingkat kesabaran 31 - 60 menit, dapat dilihat persentase pengguna smartphone sebesar 62.0\% (49 dari 79 konsumen), sedangkan pada ponsel musik sebesar $58.8 \%$ (10 dari 17 konsumen). Hasil uji menunjukkan nilai Asymp Sig. sebesar 0.23 yang mengindikasikan jenis ponsel tidak memiliki keterkaitan yang signifikan dengan tingkat kesabaran konsumen.

\section{III.4. Analisis Gap (Kesenjangan)}

Bengkel ramai adalah bengkel yang fokus dalam menyediakan fasilitas-fasilitas non-essentials untuk membuat konsumen merasa betah dan nyaman. Semua fasilitas disediakan dengan baik oleh bengkel ini seperti ruangan khusus AC dan smoking area, televisi, dan mesin pembuat kopi otomatis. Tabel 13 memperlihatkan bahwa terdapat sedikit kesenjangan pada fasilitas smoking area, televisi, akses saluran tv, keragaman dan tingkat kebaruan majalah atau koran. Hal ini mengindikasikan penyediaan fasilitas 
hampir sesuai dengan harapan dan keinginan konsumen dan tidak menjadi prioritas untuk perbaikan dan pengembangan CNE.

Tabel 13. Analisis gap pada bengkel ramai

\begin{tabular}{lcccc} 
Kategori Fasilitas & $\begin{array}{c}\text { Rata-rata } \\
\text { tertimbang } \\
\text { harapan fasilitas }\end{array}$ & $\begin{array}{c}\text { Rata-rata } \\
\text { tertimbang } \\
\text { kondisi aktual }\end{array}$ & $\begin{array}{c}\text { Gap } \\
\text { (\%) }\end{array}$ & $\begin{array}{c}\text { Prioritas } \\
\text { pengembangan } \\
\text { CNE }\end{array}$ \\
\hline Keragaman majalah/koran & 0.27 & 0.24 & 11.11 & 7 \\
Tingkat kebaruan majalah/koran & 0.28 & 0.25 & 10,71 & 8 \\
Televisi & 0.31 & 0.29 & 6.45 & 11 \\
Akses dan saluran TV & 0.30 & 0.27 & 10.00 & 9 \\
Jenis kursi & 0.39 & 0.34 & 12.82 & 6 \\
AC & 0.44 & 0.30 & 31.82 & 2 \\
Kebersihan & 0.47 & 0.36 & 23.40 & 4 \\
Toilet & 0.31 & 0.24 & 22.58 & 5 \\
Smoking area & 0.24 & 0.22 & 8.33 & 10 \\
Wifi & 0.25 & 0.16 & 36.00 & 1 \\
Kopi/minuman gratis & 0.29 & 0.22 & 24.14 & 3 \\
\hline
\end{tabular}

Fasilitas Wifi adalah fasilitas yang memiliki nilai gap terbesar, dengan nilai prioritas perbaikan tertinggi. Fasilitas ini perlu diperbaiki dan ditingkatkan dengan menambahkan bandwitch dan memperluas router internetnya, karena konsumen mengeluhkan bahwa sinyal Wifi di bengkel-bengkel AHASS ini tidak cukup kuat. Pengadaan ruangan berAC masuk dalam prioritas utama kedua pada bengkel ramai. Ruangan AC yang diharapkan konsumen adalah ruangan yang sejuk, kedap udara dari polusi knalpot sepeda motor, dan kedap suara, sehingga konsumen bisa duduk santai dan melakukan aktivitas lain yang dapat membuat betah dan nyaman. Penyediaan kopi panas, teh hangat dan minuman gratis yang lebih bervariasi di ruang tunggu juga menjadi kebutuhan bagi konsumen yang berada di ruang tunggu

Kebersihan ruangan juga menjadi hal yang penting bagi konsumen bengkel ramai dengan prioritas perbaikan nomor 4. Bengkel ramai perlu memperhatikan kebersihan ruang tunggu agar konsumen dapat merasa nyaman dan betah selama berada di ruang tunggu. Prioritas perbaikan lainnya yang dapat meningkatkan kenyamanan konsumen dalam menunggu selesainya proses pemeliharaan dan perbaikan sepeda motor dapat disimak pada Tabel 13.

Tabel 14. Analisis gap pada bengkel sangat ramai

\begin{tabular}{lcccc}
\hline \multicolumn{1}{c}{ Kategori Fasilitas } & $\begin{array}{c}\text { Rataan tertimbang } \\
\text { harapan fasilitas }\end{array}$ & $\begin{array}{c}\text { Rataan tertimbang } \\
\text { kondisi aktual }\end{array}$ & $\begin{array}{c}\text { Gap (\%) } \\
\text { pengembangan CNE }\end{array}$ & $\begin{array}{c}\text { Prioritas } \\
\text { Keragaman majalah/koran }\end{array}$ \\
Tingkat kebaruan majalah/koran & 0.28 & 0.25 & 10.71 & 9 \\
Televisi & 0.29 & 0.25 & 13.79 & 7 \\
Akses dan saluran TV & 0.31 & 0.28 & 9.68 & 10 \\
Jenis kursi & 0.29 & 0.27 & 6.90 & 11 \\
AC & 0.40 & 0.27 & 32.50 & 1 \\
Kebersihan & 0.36 & 0.16 & 20.20 & 4 \\
Toilet & 0.46 & 0.34 & 26.10 & 2 \\
Smoking area & 0.33 & 0.25 & 24.24 & 3 \\
Wifi & 0.22 & 0.19 & 18.78 & 5 \\
Kopi/minuman gratis & 0.26 & 0.12 & 11.74 & 8 \\
& 0.29 & 0.16 & 15.71 & 6 \\
\hline
\end{tabular}


Berbeda dengan pada bengkel AHASS kategori ramai pada kategori sangat ramai, prioritas perbaikan utama tidak pada kehandalan Wifi yang tersedia tetapi pada penyediaan jenis kursi yang lebih baik, sehingga lebih nyaman untuk digunakan pada waktu yang lebih lama. Namun dalam hal penyediaan fasilitas pendingin dan toilet, serta kebersihan tetap menempati prioritas yang penting bagi konsumen yang menunggu perawatan dan perbaikan sepeda motor di bengkel AHASS kategori sangat ramai.

\section{III.5. Prediksi Tingkat Kenyamanan dan Kepuasan Konsumen}

Keterkaitan antara tingkat kenyamanan dan kepuasan dengan tambahan fasilitas dapat dilihat berdasarkan data yang tersaji pada Tabel 15, dan didasarkan pada hipotesis awal bahwa terdapat hubungan yang signifikan antara kedua indikator tersebut. Berdasarkan Tabel 15 dapat dilihat bahwa sebanyak 80.0\% konsumen menginginkan peningkatan maupun penambahan fasilitas, dan sebanyak $20.0 \%$ merasa fasilitas yang ada sudah dianggap cukup sehingga tidak perlu ada penambahan fasilitas.

Tabel 15. Tingkat kenyamanan dan kepuasan terkait tambahan fasilitas

\begin{tabular}{lcccc}
\hline \multirow{2}{*}{$\begin{array}{l}\text { Tambahan } \\
\text { fasilitas }\end{array}$} & \multicolumn{2}{c}{ Peningkatan kenyamanan dan kepuasan (\%) } & \\
\cline { 2 - 4 } & $\begin{array}{c}\text { Cukup nyaman } \\
\text { dan puas }\end{array}$ & $\begin{array}{c}\text { Nyaman dan } \\
\text { puas }\end{array}$ & $\begin{array}{c}\text { Sangat nyaman } \\
\text { dan puas }\end{array}$ & Total (\%) \\
\hline Tidak perlu & 8.0 & 10.0 & 2.0 & 20.0 \\
\hline Perlu & 9.0 & 42.0 & 29.0 & 80.0 \\
- Kursi empuk & 3.0 & 2.0 & 3.0 & 8.0 \\
- Wifi & 4.0 & 25.0 & 16.0 & 45.0 \\
- Bahan bacaan & 0 & 2.0 & 2.0 & 4.0 \\
- Kantin & 1.0 & 9.0 & 6.0 & 16.0 \\
- Terapi pijat & 1.0 & 4.0 & 2.0 & 7.0 \\
\hline
\end{tabular}

Tambahan fasilitas dianggap perlu agar kenyamanan dan kepuasan konsumen dapat meningkat, hal ini dapat dilihat dari persentase konsumen yang memerlukan tambahan fasilitas adalah sebesar $36.2 \%$ yang akan merasa menjadi sangat nyaman dan puas, dari total 80 konsumen. Sedangkan konsumen yang merasa tidak perlu ada tambahan fasilitas, karena sudah merasa sangat puas dan nyaman terhadap fasilitas yang ada, adalah sebesar $10.0 \%$ dari total 20 konsumen. Penambahan fasilitas ini diharapkan dapat meningkatkan loyalitas konsumen untuk tetap melakukan perawatan sepeda motornya di AHASS yang sama dan menjadi pelanggan. Hasil tersebut juga diperkuat oleh hasil tabulasi silang antara tambahan fasilitas dengan peningkatan kenyamanan dan kepuasan konsumen, menunjukkan nilai Asymp Sig. sebesar 0.07 yang mengindikasikan adanya keterkaitan signifikan antara jenis tambahan fasilitas dengan peningkatan kenyamanan dan kepuasan konsumen.

\section{III.6. Kaitan dengan Peningkatan Loyalitas Konsumen}

Berdasarkan Tabel 16 dapat dilihat terjadinya peningkatan kenyamanan dan kepuasan apabila fasilitas-fasilitas CNE yang diinginkan konsumen diterapkan oleh AHASS. Konsumen-konsumen yang awalnya merasa tidak nyaman dan tidak puas berpindah tingkat kenyamanan dan kepuasannya menjadi jauh lebih baik. Oleh karena 
itu sebaiknya AHASS mempertimbangkan fasilitas-fasilitas tambahan tersebut agar bengkelnya dapat lebih menarik konsumen untuk memperbaiki sepeda motornya di AHASS dan meningkatkan loyalitas konsumennya.

Tabel 16. Perbandingan kenyamanan dan kepuasan konsumen terkait tambahan fasilitas

\begin{tabular}{lcccccc}
\hline \multirow{2}{*}{ Perbandingan } & \multicolumn{5}{c}{ Tingkat Kenyamanan (\%) } & \multirow{2}{*}{ Total (\%) } \\
\cline { 2 - 6 } & $\begin{array}{c}\text { Tidak } \\
\text { nyaman }\end{array}$ & $\begin{array}{c}\text { Kurang } \\
\text { nyaman }\end{array}$ & $\begin{array}{c}\text { Cukup } \\
\text { nyaman }\end{array}$ & Nyaman & $\begin{array}{c}\text { Sangat } \\
\text { nyaman }\end{array}$ & \\
\hline Kondisi aktual & 5.0 & 15.0 & 53.0 & 22.0 & 5.0 & 100 \\
Prediksi & 0 & 0 & 9.0 & 42.0 & 29.0 & 80.0 \\
Kondisi aktual & 1.0 & 4.0 & 48.0 & 39.0 & 8.0 & 100 \\
Prediksi & 0 & 0 & 9.0 & 42.0 & 29.0 & 80.0 \\
\hline
\end{tabular}

Keterkaitan antara loyalitas konsumen dengan tambahan fasilitas dapat dilihat berdasarkan data yang tersaji pada Tabel 17, dan didasarkan pada hipotesis awal bahwa terdapat hubungan yang signifikan antara kedua indikator tersebut.

Tabel 17. Loyalitas konsumen terkait tambahan fasilitas

\begin{tabular}{lccc}
\hline \multirow{2}{*}{$\begin{array}{c}\text { Tambahan } \\
\text { fasilitas }\end{array}$} & \multicolumn{2}{c}{ Loyalitas konsumen (\%) } & \multirow{2}{*}{ Total (\%) } \\
\cline { 2 - 3 } & Berkunjung kembali & Tidak berkunjung kembali & \\
\hline Tidak perlu & 18.0 & 2.0 & 20.0 \\
\hline Perlu & 79.0 & 1.0 & 80.0 \\
- Kursi empuk & 7.0 & 1.0 & 8.0 \\
- Wifi & 42.0 & 3.0 & 45.0 \\
- Bahan bacaan & 3.0 & 1.0 & 4.0 \\
- Kantin & 15.0 & 1.0 & 16.0 \\
- Terapi pijat & 7.0 & 0 & 7.0 \\
\hline
\end{tabular}

Berdasarkan Tabel 17 dapat dilihat bahwa sebanyak 80.0\% konsumen menginginkan peningkatan maupun penambahan fasilitas, dan sebanyak $20.0 \%$ merasa fasilitas yang ada sudah dianggap cukup sehingga tidak perlu ada penambahan fasilitas. Tambahan fasilitas dianggap bukan menjadi hal utama agar konsumen loyal dan menjadi pelanggan, hal ini dapat dilihat dari persentase konsumen yang tidak memerlukan tambahan fasilitas adalah $18 / 20$ yaitu sebesar $90.0 \%$ yang akan tetap berkunjung kembali, meskipun tidak ada penambahan fasilitas. Hasil tabulasi silang antara tambahan fasilitas dengan loyalitas konsumen, menunjukkan nilai Asymp Sig. sebesar 0.74 yang mengindikasikan tidak adanya keterkaitan signifikan antara jenis tambahan fasilitas dengan loyalitas konsumen.

Terdapat adanya kemungkinan hubungan yang signifikan antara loyalitas konsumen dengan alasan utama untuk melakukan servis. Data yang tersaji pada Tabel 18 memperlihatkan bahwa sebanyak 92.0\% konsumen akan berkunjung kembali, dan sebanyak $8.0 \%$ yang tidak ingin berkunjung kembali ke AHASS yang sama. Alasan utama konsumen melakukan servis di AHASS tersebar merata antara kualitas pelayanan yang memuaskan, lokasi strategis dan mudah dijangkau, dan hasil perbaikan yang bagus. AHASS harus tetap mempertahankan kualitas pelayanannya agar konsumen terus kembali berkunjung dan menjadi pelanggan. Hasil tabulasi silang antara tambahan fasilitas dengan loyalitas konsumen, menunjukkan nilai Asymp Sig. 
sebesar 0.15 yang mengindikasikan adanya keterkaitan signifikan antara alasan utama servis dengan loyalitas konsumen.

Tabel 18. Loyalitas konsumen terkait alasan utama servis

\begin{tabular}{lccc}
\hline \multirow{2}{*}{ Alasan utama } & \multicolumn{2}{c}{ Loyalitas konsumen (\%) } & \multirow{2}{*}{ Total (\%) } \\
\cline { 2 - 3 } & Berkunjung kembali & Tidak berkunjung kembali & \\
\hline Biaya murah & 2.0 & 0 & 2.0 \\
Suasana nyaman & 6.0 & 0 & 6.0 \\
Kualitas pelayanan & 32.0 & 0 & 32.0 \\
Lokasi strategis & 27.0 & 3.0 & 30.0 \\
Hasil perbaikan & 22.0 & 5.0 & 27.0 \\
Lainnya & 3.0 & 0 & 3.0 \\
Total (\%) & 92.0 & 8.0 & 100 \\
\hline
\end{tabular}

\section{III.7. Implikasi Manajerial}

1. AHASS dalam meningkatkan kualitas pelayanannya tidak lagi cukup memfokuskan hanya pada perawatan dan perbaikan sepeda motor saja (core business) tetapi juga pada kenyamanan konsumen pada saat menunggu

2. Kondisi dan kebutuhan akan perbaikan fasilitas pada setiap kategori AHASS berbeda, oleh karenanya diperlukan kemampuan untuk menilai kebutuhan pengembangan fasilitas untuk peningkatan kenyamanan konsumen saat menunggu pada setiap AHASS.

3. Perbaikan dan pengembangan fasilitas untuk peningkatan kenyamanan konsumen saat menunggu perlu diarahkan dengan menerapkan prinsip dasar CNE, menyediakan fasilitas yang dibutuhkan namun tidak terkait langsung dengan kegiatan inti.

\section{Kesimpulan}

Model CNE telah diterapkan oleh AHASS secara terbatas, namun untuk meningkatkan daya saing masih diperlukan upaya yang sungguh-sungguh untuk memperbaikinya, sehingga sebagian besar konsumen tidak hanya menilai fasilitas yang ada pada ruang tunggu cukup nyaman, tetapi menjadi nyaman atau bahkan sangat nyaman.

Hal-hal yang perlu mendapat prioritas dalam penerapan prinsip CNE di AHASS untuk meningkatkan kenyamanan saat menunggu adalah penyediaan fasilitas Wifi yang handal, ruangan berpendingin (AC) dan tenang (kedap suara), kebersihan lingkungan, toilet yang bersih, ketersediaan minuman bervariasi, serta kursi tunggu yang nyaman, terutama pada AHASS dengan kategori sangat ramai. Masih diperlukan tambahan fasilitas lain untuk meningkatkan kenyamanan konsumen saat menunggu.

Penilaian kepuasan konsumen dan loyalitas lebih terkait pada kualitas hasil kerja perbaikan dan perawatan (essensial) sepeda motor. Kepuasan dan kenyamanan pada fasilitas yang tersedia di ruang tunggu tidak berkaitan dengan loyalitas konsumen pada AHASS. Namun terdapat hubungan yang signifikan antara alasan untuk memilih melakukan servis sepeda motor di suatu AHASS dengan loyalitas konsumen. Melalui 
komunikasi bisnis yang intensif, kondisi tempat tunggu yang nyaman bisa menjadi pertimbangan utama dalam memilih tempat servis.

\section{Daftar Pustaka}

[AHM] Astra Honda Motor. 2013. AHASS di Kota Bogor Tahun 2013 [Internet]. [diunduh 2013 April 2]. Tersedia pada: http://astra-honda.com/index.php/ jaringan/ seacrh/2/121

[AISI] Asosiasi Industri Sepeda Motor Indonesia. 2013. Jumlah produksi sepeda motor di Indonesia (1996 - 2013) [Internet]. [diunduh 2013 April 2]. Tersedia pada : http://www.aisi.or.id/statistic/

Helgesen O. 2006. Are Loyal Customers Profitable? Customer Satisfaction, Customer (Action) Loyalty and Customer Profitability at the Individual Level. Jurnal Manajemen Pemasaran [internet]. [diunduh 2013 sept 13]; 22(3): 245-266. Tersedia pada: http://web.ebscohost.com.

Lund P. 2007. The Absolutely Critical Non-Essentials. Capalaba (AU): Solutions Pr.

Rini ES. 2009. Menciptakan Pengalaman Konsumen dengan Experiental Marketing. Jurnal Manajemen Bisnis [internet]. [diunduh 2013 sept 13]; 2(1): 15-20. Tersedia pada: http:// repository.usu.ac.id.

Yamit Z. 2010. Manajemen Kualitas Produk dan Jasa. Yogyakarta (ID): Ekonisia.

Ziqi Wu, Robson S, Hollis B. 2013. The Application of Hospitality Elements in Hospitals. The Journal of Healthcare Management [internet]. [diunduh 2013 Sept 13]; 58(1): 47-62. Tersedia pada: http://web.ebscohost.com/ 